\title{
2014 À altura de nossas esperanças e aspirações
}

Maria Cristina Castilho Costa

Doutora em Ciências Sociais pela FFLCH-USP, livre-docente em Ciências da Comunicação pela ECA-USP, professora associada 3 da ECA-USP, coordenadora do Observatório de Comunicaşão, Liberdade de Expressão e Censura da USP e autora do livro A Censura em Cena, publicado pela Edusp e Imprensa Oficial.

E-mail: criscast@usp.br

Resumo: A autora utiliza como referência a obra do historiador Eric Hobsbawm para apresentar os artigos desta edição da revista Comunicação \& Educação, a primeira a ser preparada em tempo real para versões on-line e impressa. Tal mudança possibilitará um maior alcance, chegando aos leitores mais distantes, de diferentes regiões e instituições, permitindo assim que a Comunicação e seus recursos alavanquem os processos pedagógicos, educativos e de desenvolvimento humano, objetivo principal dos pesquisadores, professores e estudiosos desse campo, que é interdisciplinar.

Palavras-chave: Comunicação e Educação; Eric Hobsbawm; processos pedagógicos; desenvolvimento humano; interdisciplinaridade.
Abstract: The author uses as a reference the works of the historian Eric Hobsbawm to present the articles of this issue of the magazine Communication and Education, the first one to be simultaneously published on-line and printed. This change provides a wider scope, reaching farther readers, from different places and institutions, allowing Communication and its resources to leverage pedagogical, educational and human development processes, which are the main objectives of researchers, teachers and scholars from this field of study, which has an interdisciplinary nature.

Keywords: Communication and Education; Eric Hobsbawm; pedagogical processes; human development; interdisciplinarity.

Sempre que um ano chega ao fim, temos um sentimento peculiar que vem, em parte, da consciência de termos encerrado uma etapa, usando recursos e energias, próprios e dos outros, de maneira a produzir, finalizar, entregar, encerrar pelo menos parte dos frutos que tivemos a intenção do obter no início do ano. Não importa quão positiva seja a conta a que chegamos ou o saldo que por ventura obtivemos, nossa sensação é de incompletude e falta, ainda que misturada à satisfação das vitórias alcançadas.

Diferente disso é o sentimento que temos no início do ano, passadas as festas, as cerimônias de passagem e as confraternizações. Estamos abertos ao novo, cheios de vigor e garra para implementar novos trabalhos e conquistar outras vitórias. E é com esse sentimento de otimismo, confiança e vontade de agir que venho apresentar aos leitores o primeiro número de 2014 da revista Comunicação Ė Educação. Por si só, já é inovador - trata-se do primeiro volume 
já produzido para publicação on-line, concomitante com a versão impressa, elaborada pela batuta dos editores Adilson Citelli e, desde 2013, Roseli Fígaro. Tais inovações refletem as necessidades dos novos tempos, de permitir que esse trabalho chegue a todos os interessados via comunicação em rede, que possa ser dinâmico, ágil, possibilitando, inclusive, uma relação mais próxima com o nosso leitor. Por tudo isso, o otimismo é grande, principalmente no que diz respeito à maior facilidade de divulgação e portabilidade. Nossos ensaios estarão alcançando os mais distantes leitores, as mais diferentes regiões, as mais variadas instituições, permitindo que a Comunicação, ou seus recursos, possam alavancar os processos pedagógicos, educativos e de desenvolvimento humano.

Portanto, é esse o sentimento que transparece ao iniciar esta Apresentação - o sentimento da passagem, sentimento que nos acomete quando vislumbramos a experiência acumulada e o trabalho realizado, ao lado daquilo que se anuncia e que ainda está por vir. E, para refletir de forma pertinente esse sentimento híbrido de passado e presente, vou me referir a um livro publicado em 2009 por Eric Hobsbawm chamado $O$ novo século, pequena obra que divulga entrevista realizada pelo jornalista Antonio Polito com esse grande historiador britânico, falecido em 2012.

Hobsbawm foi o autor de muitos estudos importantes sobre o capitalismo no Ocidente, como Era das revoluções, Era do capital e A era dos impérios. Sobre o século XX, escreveu um dos livros mais importantes e citados: Era dos extremos - O breve século XX, no qual analisa os acontecimentos políticos, econômicos e culturais que, entre 1914, quando teve início a Primeira Guerra Mundial, e 1991, com o fim da União Soviética, marcaram a sociedade contemporânea. Publicado, esse texto tornou-se referência para todos que buscam entender a chamada pós-modernidade, período em que ocorre drástica reestruturação das forças produtivas da sociedade com a globalização e aquilo que ficou conhecido como capitalismo pós-industrial, caracterizado pela produção em sistemas informatizados ou plataformas produtivas. Suas análises de observador participante, como ele mesmo se intitula, levam em conta conquistas e derrotas, conflitos e alianças, esperanças e decepções vividos pelos mais diferentes países durante um século marcado, como o título sugere, por drásticas transformações, muitas das quais cada vez mais evidentes neste século XXI. E justamente para tratar dessas diferenças e das peculiaridades do novo século, o livro mais recente, a que me referi inicialmente, provoca o historiador para a análise de previsões feitas em obras anteriores. Diante dessa provocação, Hobsbawm é cauteloso: afirma que, em relação ao futuro, sempre devemos pensar no imponderável, pois ele sempre existirá, mas que é papel do historiador buscar tendências e averiguar suas possibilidades e viabilidades. Assim, ele reafirma que, inquestionavelmente, estamos vivendo um novo século.

Nas páginas seguintes, Polito indaga sobre os estados nacionais e a globalização, sobre as formas atuais de mobilização política, novas formas de terrorismo e a internacionalização econômica, sobre a emergência de forças 
importantes que ameaçam a hegemonia do ocidente, a respeito das formas contemporâneas da comunicação em rede, as desigualdades sociais e os anseios populares. Hobsbawm, como sempre, responde a tudo com clareza e ponderação, mostrando que efetivamente são outros os paradigmas que acionam as nossas relações com os meios e entre nós, permitindo pensar que um novo século emerge das forças conflitadas do passado. Como aquele, este século é cheio de paradoxos e dissensões.

\section{E A COMUNICAÇÃO E A EDUCAÇÃO?}

Bem, mas o que tudo isso tem a ver com Comunicação e Educação, com nossa revista e com as mutações de um novo ano que ela anuncia? Escrevemos sobre os livros de Hobsbawm porque a última pergunta feita pelo jornalista, em O novo século, com a qual encerra sua obra, é muito sensível e vou transcrevê-la:

Em seu término, o século XX proporcionou-lhe a felicidade de ter um neto, batizado de Roman. Ele será plenamente um filho do século XXI, como o senhor o foi do século XX. Do alto de sua experiência, quais são as suas esperanças para o pequeno Roman?

"Ele não terá outra alternativa a não ser viver em seu século", respondeu o historiador, "tal como não tive alternativa a não ser viver no século XX". Ou seja, Hobsbawm reconhece que, apesar de todo seu poder de análise e seu esforço por predizer o futuro, não sabe o que poderia sugerir a ele. Diante disso, ele apenas declara:

“... espero que Roman possa encontrar uma sociedade que esteja à altura de suas esperanças e aspirações. Isso é o que todo mundo merece ter no século XXI”

Concordando absolutamente com essa afirmação do historiador, chegamos a nosso objetivo - por um lado, dizer que esses são os nossos votos para os leitores que agora chegam à nossa revista, e, por outro, afirmar que o desejo do historiador só se tornará realidade através de uma eficiente ação com foco no desenvolvimento humano. E esse é o objetivo principal dos pesquisadores, professores e estudiosos desse campo interdisciplinar que é Comunicação e Educação. Colocar os conhecimentos obtidos com as Ciências da Comunicação para que o ser humano possa se afirmar em seu processo civilizatório, é o grande objetivo do nosso trabalho que envolve não só a elaboração dessa revista, como a formação de educomunicadores em diferentes níveis - graduação, especialização e pós-graduação.

Bem, considerando apresentado em termos gerais este novo número da revista Comunicação $\mathcal{E}^{2}$ Educação, vamos ver que textos foram selecionados para os leitores, os diversos "Romans" que esperam por nosso trabalho.

1. HOBSBAWN, Eric. O novo século - Entrevista a Antonio Polito. São Paulo: Cia. das Letras, 2009 , p. 174. 
comunicação \& educação • Ano XIX • número 1 • jan/jun 2014

\section{A REVISTA COMUNICAÇÃO \& EDUCAÇÃO}

Recuperando parte da já longa história da revista Comunicação Ė Educação, Adilson Citelli, que acompanha desde o início a criação e desenvolvimento deste periódico, na condição de um de seus editores, reafirma os princípios que norteiam esta publicação que se constitui, segundo suas palavras, na mais tradicional publicação em sua área. O autor recupera a motivação dos professores do Departamento de Comunicações e Artes da ECA-USP, que almejavam com esta produção contribuir para a melhoria da educação pública e, ao mesmo tempo, favorecer a democratização da Comunicação.

Citelli conta que, a partir desses objetivos, criou-se um modelo único e próprio de periódico, o qual, durante duas décadas, garantiu sua viabilidade econômica e sua liberdade acadêmica. Assim, temas como leitura crítica dos meios, inovações tecnológicas, cultura e recepção midiáticas, estruturas discursivas e possíveis mudanças no sistema educacional a partir das conquistas no campo da Comunicação, estiveram sempre no centro das atenções da revista.

Assim, iniciando mais uma década de produção e realização, a revista Comunicação $\mathcal{E}$ Educação vem reiterar seus fundamentos e objetivos e começa 2014 com a retrospectiva elaborada por seu editor.

\section{Comunicação}

Abordando de forma central as questões ligadas às Ciências da Comunicação, o presente volume da revista Comunicação $\mathcal{E}$ Educação nos oferece ensaios, pesquisas e entrevistas. Marcelo Ernandez Macedo escreveu interessante artigo intitulado "Notas sobre os conceitos de comunidade, comunicação comunitária e dialogia" no qual disserta sobre o sentido de comunicação comunitária. No texto, o autor mostra as transformações havidas com o conceito de comunidade que, originariamente, na Sociologia, designava uma forma específica de coletividade, de caráter pessoal e próximo, opondo-se ao significado de sociedade, termo próprio para designar grupos que se relacionam de forma mais impessoal e convencional. Na atualidade, o conceito se modifica, pressupondo grupos unidos por vizinhança, sentimentos e objetivos comuns. Entretanto, o autor discute também a influência dos novos meios de comunicação e da comunicação em rede para novos conteúdos que ora aderem ao conceito. Nesse cenário de transformações sígnicas, comunicação comunitária também exige redefinições. Assim, baseado em autores como Ciro Marcondes Filho e Cicilia Peruzzo, ele discute o conceito que, em sua ótica, envolve necessariamente dialogia.

A entrevista deste número da revista Comunicação Ẽ Educação é com Venício Lima e tem por título "Em defesa da democratização dos meios de comunicação". Autor de importantes textos discutindo Comunicação e o monopólio dos meios de comunicação pelas grandes agências, esse estudioso de Mídia e Política, afirma que todo processo de democratização real deve, na atualidade, envolver a comunicação. O autor considera o sistema de comunicação brasileiro 
oligopolizado, resultando em uma comunicação que exclui a maior parte da população do acesso à informação. Comparando a situação brasileira com a Argentina, ele reconhece que estamos ainda muito longe das discussões e mobilizações que lá ocorrem, embora reconheça que são grandes as diferenças entre os dois países. Defensor da liberdade de expressão, ameaçada pelo poder monopolizador das grandes corporações de mídia, ele se diz um Dom Quixote, brigando contra moinhos de vento.

Érica Schneider de Vilhena Pedroza é a autora de ensaio que discute como a Comunicação é inserida pelos professores nas atividades do ensino médio. Entrevistando professores de escolas públicas e privadas, Pedroza evidencia as dificuldades de compreensão do conceito de comunicação e, mais ainda, de sua transposição para atividades práticas educativas. Ora se aproximando do campo da linguagem, ora resvalando para o da cultura, os professores expressam suas dificuldades. Com base em teóricos como Mikhail Bakhtin e Jesús Martín-Barbero, a autora procura discutir e avaliar essas interpretações e práticas.

\section{Comunicação audiovisual - cinema}

Se a pesquisa de Pedroza busca saber como os professores de ensino médio, no Brasil, inserem os conhecimentos de comunicação em suas práticas pedagógicas, o artigo internacional relata pesquisa realizada na Espanha: "O grau de competência em comunicação audiovisual entre os cidadãos da Andaluzia (Espanha)". Os autores, Ignacio Aguaded e Rocío Cruz-Díaz, nos apresentam resultados dessa investigação que constata a baixa competência dos andaluzes em interpretar e se expressar por meio da linguagem audiovisual. Em suas considerações finais, os autores destacam que essa baixa competência diz respeito tanto às características estéticas como linguísticas e ideológicas. Para esse quadro, preconizam a introdução de disciplinas formativas em educação para os meios e educação audiovisual nos mais diferentes graus de escolaridade infantil, primária e secundária.

Com o objetivo justamente de melhorar a competência de professores e alunos na compreensão e expressão audiovisual, Claudia Mogadouro nos presenteia com um bom texto intitulado "O cinema reinventando a escola - Um diálogo da Educomunicação com o filme A invenção de Hugo Cabret". Doutora em Ciências da Comunicação com tese sobre o uso do cinema da educação, defendida na ECA-USP, Mogadouro defende a ideia de que a prática cinematográfica na escola é uma forte aliada para uma maior interação dos educadores com a infância e a juventude. E para discorrer sobre isso ela se vale do premiadíssimo filme de Martin Scorsese.

Ao encontro do que propõe Mogadouro, Maria Inês Carlos Magno apresenta resenha do livro 1984, de George Orwell, cuja releitura e apreciação ela sugere, assim como do filme homônimo do diretor Michel Anderson. 1984, que completa 66 anos, é um dos livros mais lidos de sua época, abordando 
um tema que é cada vez mais recorrente: o excessivo controle que as formas autoritárias de poder exercem sobre a sociedade na qual se impõem. Escrito em período histórico polêmico, quando as mais diferentes ideologias políticas procuravam imperar sobre o mundo, disputando o domínio do planeta, Orwell adverte para o perigo da perda de nossa liberdade em virtude de mecanismos cada vez mais poderosos de fiscalização e controle. Se as previsões de Orwell não se concretizaram da forma como prediz no livro, o advento das mídias digitais acirram as controvérsias em torno do tema controle/liberdade, garantindo a atualidade da obra.

\section{Comunicação audiovisual - televisão e mídias digitais}

“Memória e ficção televisiva ibero-americana” é o título da resenha que Ligia Maria Prezia Lemos realiza sobre a publicação do Anuário 2013, do Observatório Ibero-americano da Ficção Televisiva, Obitel. Esse projeto intercontinental de países latino-americanos e ibéricos há quase uma década promove o estudo da produção televisiva em seus aspectos midiático, cultural, artístico e comercial. Analisando as tendências atuais da produção e do consumo televisivo nos países ibero-latino-americanos, Prezia destaca a crescente popularização da telefonia móvel e da internet como formas de consumo midiático, o que tem modificado substancialmente a relação do público com a televisão e com a telenovela. Vale a pena conferir.

Dulce Márcia Cruz e Rafael Marques de Albuquerque são os autores do trabalho publicado na seção Experiência que também aborda a emergência das mídias digitais na comunicação. $\mathrm{O}$ artigo intitulado "A produção de jogos eletrônicos por crianças: narrativas digitais e o RPG Maker" traz o relato de resultado de oficina para o desenvolvimento de videogames com jovens entre 11 e 12 anos, em escola de Florianópolis. O foco de suas análises é o estudo das possibilidades narrativas desses jogos.

\section{Livros didáticos e não didáticos}

"Manuais de Educomunicação: subsídios das organizações sociais e da política pública" é o título da resenha de autoria de Ismar de Oliveira Soares e Daniele Próspero, visando levar a público o conteúdo de três manuais de Educomunicação. Estes buscam traçar o caminho entre a teoria e a prática e analisam experiências realizadas na educação formal e informal bem como a contribuição de importantes autores da América Latina para esse campo do conhecimento. O que une todo esse variado e complexo conteúdo é a proposta do diálogo tanto na escola como na comunidade.

Com isso, voltamos ao início de nossa Apresentação, à recuperação da história da revista Comunicação E્ Educação e de sua contribuição para o desenvolvimento 
dos estudos que aliam a comunicação à prática pedagógica, a análise teórica à intervenção na sociedade, a produção ao consumo midiático. Para tornar isso evidente, nada melhor do que o texto de Luciana Coutinho Pagliarini de Souza e Maria Ogécia Drigo: "Representações visuais da mulher afrodescendente em livros didáticos". Trata-se de um estudo que analisa criticamente diferentes tipos de imagens de mulheres afrodescendentes que ilustram os livros didáticos que compõem a lista do PNLD-2011. A autora relata os resultados dessa pesquisa financiada pela Fapesp e interpreta os diferentes significados de diversas opções estéticas, políticas e ideológicas.

E, para encerrar nosso convite à leitura deste volume, voltamos a dizer que neste início de 2014 há muito de passado, de herança recebida, de caminho percorrido e de trabalho realizado. Mas há, também, muito de futuro, de temas a visitar, de autores a considerar, de diálogo a se estabelecer. A nós, só resta convidar os leitores para a continuidade dessa troca.

\section{REFERÊNCIAS}

Hobsbawm, Eric. Era dos extremos - O breve século XX. São Paulo: Cia. das Letras, 1995.

A era das revoluções. São Paulo: Paz e Terra, 2009.

. A era do capital. São Paulo: Paz e Terra, 2009.

_. A era dos impérios. São Paulo: Paz e Terra, 2009.

. O novo século - Entrevista a Antonio Polito. São Paulo: Cia. das Letras, 2009. 